\title{
Chronic lateral ankle instability: a current concepts review
}

\author{
Ziyaad Mayet, ${ }^{1 *}$ (iD Paulo NF Ferrao, ${ }^{1}$ Nikiforos P Saragas, ${ }^{1}$ Richard Paterson, ${ }^{1}$ Sebastian KM Magobotha, ${ }^{2}$ \\ Alwich Alexander, ${ }^{1}$ Hooman Eshragi, ${ }^{1}$ Hossein Ittehadi, ${ }^{1}$ Mohammed A Khademi, ${ }^{1}$ Mohammed Mehtar, ${ }^{1}$ \\ Makgabo J Tladi, ${ }^{1}$ Andrew Strydom, ${ }^{1}$ Matthew Workman ${ }^{1}$
}

${ }^{1}$ Linksfield Foot and Ankle Fellowship Programme; Division of Orthopaedics, University of the Witwatersrand, Johannesburg, South Africa

2 Division of Orthopaedics, University of the Witwatersrand, Johannesburg, South Africa

${ }^{*}$ Corresponding author: bonedoc.zm@gmail.com

Citation: Mayet Z, Ferrao

PNF, Saragas NP, Paterson R, Magobotha SKM, Alexander A, Eshragi $\mathrm{H}$, Ittehadi $\mathrm{H}$, Khademi MA, Mehtar M, Tladi MJ, Strydom A, Workman M. Chronic lateral ankle instability: a current concepts review. SA Orthop J 2021;20(2):106-113. http://dx.doi. org/10.17159/2309-8309/2021/ v20n2a7

Editor: Prof. Leonard C Marais

Received: August 2020

Accepted: January 2021

Published: May 2021

Copyright: ๑ 2021 Mayet Z.

This is an open-access article distributed under the terms of the Creative Commons Attribution Licence, which permits unrestricted use, distribution and reproduction in any medium, provided the original author and source are credited.

Funding: No funding was received for this study.

Conflict of interest: The authors declare they have no conflicts of interest to declare that are directly or indirectly related to the research.

\begin{abstract}
Injuries to the lateral ankle ligaments are quite common, with a reported incidence of up to $22 \%$ of all sports injuries, and $85 \%$ of all ankle sprains. Most of these are effectively managed using nonoperative measures in the acute setting. Approximately $20 \%$ of patients will, however, develop chronic lateral ankle instability (CLAI).
\end{abstract}

Although the anatomy and biomechanics are well documented, more recently, the concepts of the lateral talofibular calcaneal ligament (LTFCL) and microinstability have been described.

For those who develop CLAI, a full assessment is mandatory to not only search for correctable risk factors (malalignment), but also to differentiate between functional and mechanical instability. Associated injuries need to be excluded, such as osteochondral lesions of the talus. Rotational ankle instability is a new concept that needs to be considered.

Patients who present with CLAl are initially managed conservatively in the form of functional rehabilitation. This management is especially effective in patients with functional instability. Surgery is generally indicated after failed conservative management in patients with objective mechanical instability. The elite athlete is a relative indication to performing surgery early.

The choice of surgical procedure is made on an individualised basis, although open anatomical procedures remain the gold standard. Non-anatomical procedures are no longer recommended. Newer minimally invasive and endoscopic techniques show promise in experienced hands but there is only limited evidence to support its use at present. The use of a suture tape as an augment is reserved for specific indications and should not be used routinely.

Level of evidence: Level 5

Keywords: chronic lateral ankle instability, ATFL, CFL, functional rehabilitation, Broström, surgical procedures for lateral ankle ligaments

\section{Introduction}

Ligamentous injuries of the ankle, commonly called ankle sprains, are very common. There is a reported incidence of up to $22 \%$ of all sports injuries. An injury of the lateral ligamentous complex from an inversion sprain accounts for $85 \%$ of ankle sprains. This injury occurs when the foot is forced into inversion while the ankle is plantarflexed. Most of these injuries will present to casualty or primary healthcare settings for evaluation. ${ }^{1-3}$

Most acute injuries, if treated appropriately with conservative management, will recover. ${ }^{4}$ There are, however, those that do go on to have chronic problems. Residual pain and instability are the most common complaints as confirmed in a cohort of athletes by Yeung et al. ${ }^{5}$ The incidence was $30.2 \%$ and $20.4 \%$ respectively. The authors also reported that as the number of recurrent sprains increased, so did the frequency of residual symptoms. ${ }^{1,5}$
Approximately $20 \%$ of patients can proceed to develop chronic instability. Recommended management for chronic lateral ankle instability ( $\mathrm{CLAI}$ ) is conservative, with operative treatment being indicated for failed conservative management. Recent literature reported poor response to conservative management in patients with mechanical instability, unlike functional instability. ${ }^{5-9}$ There is much renewed interest in the surgical management of CLAI. This is partly due to the recent advances in minimally invasive and arthroscopic surgery. This was described as 'a big wave is coming' by authors of a recent editorial. ${ }^{10}$

\section{Anatomy}

The ankle joint is stabilised by a combination of the bony mortice and the supporting soft tissue. This creates a hinge-like joint with the talus gliding in the mortise where the wedge shape of the trochlea 


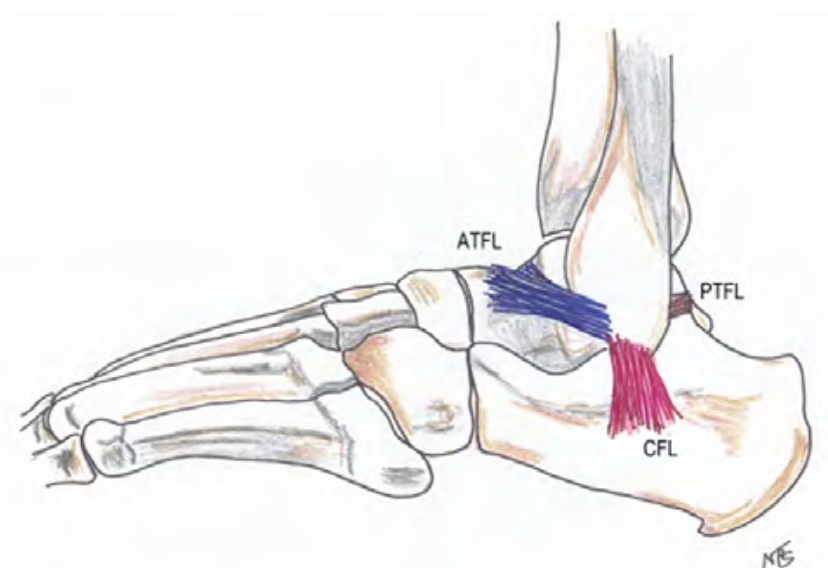

Figure 1. Lateral collateral ligament complex (artwork courtesy of Prof. NP Saragas)

of the talus allows the talus to internally rotate and supinate as the ankle plantar flexes. This sets up a complex mechanical interaction between bones, ligaments and tendons. ${ }^{7,11}$

Soft tissue stability is also provided by three ligamentous complexes: the deltoid, the syndesmosis and the lateral collateral ligament complex. The lateral complex is made up of three ligaments: the anterior talofibular ligament (ATFL), calcaneofibular ligament (CFL) and posterior talofibular ligament (PTFL) (Figure 1). The ATFL is the weakest of the three with a tensile strength of about $140 \mathrm{~N}$. It lies almost horizontal, with the ankle in a neutral position, as it runs from the anterior part of the lateral malleolus to the talar neck. As the ankle moves into plantarflexion the ATFL tightens and comes to lie almost vertical. In this position it is vulnerable to injury under excessive internal rotation stress or inversion and is the first of the ligaments injured in a sprain. The CFL runs from the tip of the lateral malleolus to the calcaneus in a slightly posterior oblique direction forming an angle of approximately $105^{\circ}$ to the ATFL. ${ }^{12}$ Progression of the injury leads to CFL injury in about $20 \%$ of cases. Injury to the CFL has also been implicated in subtalar instability. ${ }^{13}$ The ATFL is intracapsular while the CFL is extracapsular. The PTFL is injured in less than $10 \%$ of cases. ${ }^{11}$ Besides these static structures, the tendons around the ankle also aid in the stability of the ankle and are the focus in conservative management. ${ }^{7}$

With the advent of minimally invasive surgery, there has been a renewed interest in the anatomy of the ligamentous complex by various authors. Matsui et al., in a meta-analysis of cadaver studies, looked at anatomical features for the development of endoscopic and minimally invasive reconstructions. The ATFL was found to have one bundle in $61.6 \%$ of specimens, two bundles in $35.7 \%$ and three bundles in $2.7 \%$. The fibular origin was on the inferior part of the anterior border of the fibula, approximately $50 \%$ between the anterior tubercle and inferior tip. The obscure tubercle, or anteroinferior tubercle of the fibula, may be used as a landmark for this point. The talar insertion is anterior to the lateral articular surface. The fibular origin of the CFL is just distal to that of the ATFL, with both ligaments sharing a single confluent footprint on the anterior border of the fibula. The CFL runs from the tip of the fibula, under the peroneal tendons, and attaches to the lateral surface of the calcaneus. ${ }^{13}$

Vega et al. described the anatomy of the ATFL and CFL in 32 cadaveric specimens. All specimens showed the ATFL to have two fascicles, superior and inferior. The superior fascicle was shown to be a distinct anatomical structure that tightened in plantarflexion. The inferior fascicle was shown to be isometric with the CFL and did not change in length with plantarflexion. Furthermore, the inferior fascicle is joined to the CFL by arciform fibres. The authors stated that this was one structure and called it the lateral talofibular calcaneal ligament (LTFCL). The superior fascicle was found to be intracapsular and therefore thought to have poor healing potential after a rupture. The inferior fascicle and CFL are extracapsular. The authors hypothesised that a tear of the LTFCL causes classic instability while an isolated tear of the superior fascicle results in microinstability. This theory is based on the supposition that the superior fascicle, being intra-articular, will probably not heal. The authors also suggested that the LFTCL complex explains why an isolated ATFL repair gives good results despite there being involvement of both ATFL and CFL. ${ }^{14}$

\section{Pathomechanics}

Sprains of the lateral ligaments have varying degrees of injury. Acutely this is graded as stretching, partial tear or complete tear of the ligament. ${ }^{2}$ Acute sprains do not only cause injury to the ligaments, but also disrupt normal neural processes. This is caused by disruption of capsular mechanoreceptors that can lead to the loss of afferent nerve function and ankle motor coordination. These disrupted neural processes can result in functional CLAI. ${ }^{15,16}$

CLAl can result from functional or mechanical causes. Functional instability is present in patients complaining of the ankle giving way but have no clinical and radiographic evidence of instability. These patients therefore have a perceived sense of instability with no anatomical deficit. Factors leading to this may include impaired proprioception, diminished neuromuscular control, compromised strength, decreased postural control, tight Achilles tendon and weak peroneal muscles. In contrast, with mechanical instability there is clinical evidence of instability which is due to the lateral ligaments being incompetent or stretched out. These patients will have positive stress tests on clinical examination and obvious instability on radiography due to the incompetent anatomical structures. Surgical management is not indicated for isolated functional instability, and this is treated with nonoperative measures, including proprioceptive rehabilitation. ${ }^{4}$ However, in reality, CLAI tends to be due to a combination of both mechanical and functional instability. 4,7 This supports the concept of initial conservative management and surgery being reserved for failed conservative management. ${ }^{17}$

The concept of rotational ankle instability (RAI) has been described by Buchhorn et al. and Vega et al. as a combination of lesions in the medial (anterior deltoid ligament) and lateral ligament complex. The condition is defined as an abnormal increase of talar rotation within the tibiofibular mortise due to an injury in the most anterior component of the deltoid ligament secondary to a chronic deficiency of the lateral collateral ligaments. This is observed during arthroscopy as a deltoid 'open book' tear of the most anterior component of the deltoid ligament as it separates from the medial malleolus while proximal attachments remain intact, when applying passive internal rotation of the tibio-talar joint. ${ }^{18,19}$

A limited number of patients with CLAI may have a partial deltoid injury; the authors highlight the high index of suspicion in recognising this injury. It is often difficult to assess clinically especially in the absence of medial symptoms, only to become apparent once isolated repair of the lateral ligament is performed. There is no specific clinical test to diagnose RAI. An MRI is imperative when RAI is suspected in patients with CLAl and arthroscopic evaluation of the deltoid ligament is advisable prior to treating the torn lateral ligament. The benefit of repairing both ligaments is emphasised in studies by Buchhorn et al. and Vega et al. ${ }^{18,19}$

Ankle sprains may be associated with several other pathologies. There is an overall incidence of $93 \%$ of associated injuries. ${ }^{4}$ DiGiovanni et al., in a retrospective review of 61 patients with CLAl, found that no patient had isolated ligament injuries. Peroneal tendon and retinacular pathologies, and anterolateral impingement 
occurred most often. Their findings are summarised in Table $I$. Of note is a $23 \%$ incidence of osteochondral lesions of the talus (OLT). ${ }^{20}$ The incidence of OLT has been reported as high as $98 \% .{ }^{21}$

Table I: Associated injuries ${ }^{20}$

\begin{tabular}{|l|c|}
\hline Injury & Incidence \\
\hline Peroneal tenosynovitis & $77 \%$ \\
\hline Attenuated peroneal retinaculum & $54 \%$ \\
\hline Peroneus brevis tear & $25 \%$ \\
\hline Anterolateral impingement lesion & $67 \%$ \\
\hline Ankle synovitis & $49 \%$ \\
\hline Intra-articular loose body & $26 \%$ \\
\hline Talar osteochondral lesions & $23 \%$ \\
\hline Medial ankle tendon tenosynovitis & $5 \%$ \\
\hline
\end{tabular}

\section{Clinical evaluation}

\section{History}

Patients usually present with a history of giving way or rolling of the ankle. There is often a preceding history of trauma. Important questions in the history that need to be asked are related to the

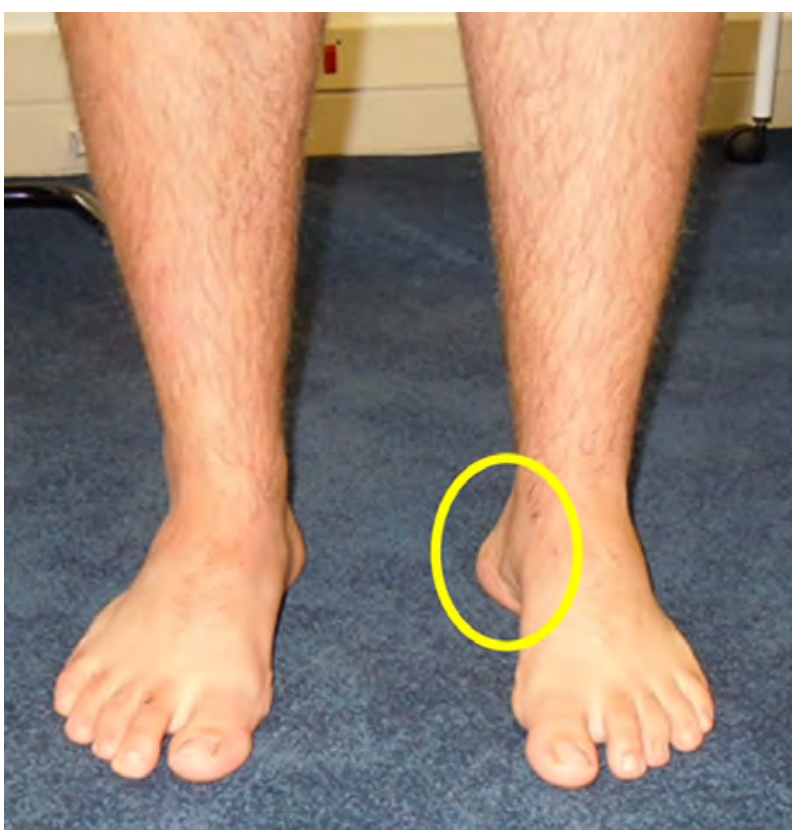

Figure 2. The 'peek-a-boo' sign for hindfoot varus chronology of the sprains and the frequency of recurrent sprains, as well as inciting events like sport or uneven surfaces. Associated symptoms may include swelling, pain and sometimes locking of the ankle especially if there is an associated osteochondral lesion. A past medical history and family history of neuromuscular and ligamentous problems is important. Footwear and orthotics should not be forgotten. Lastly, a history of previous treatment modalities or interventions should be asked about, as well as any problems with the opposite ankle. An occupational and sporting history is mandatory. ${ }^{6}$

\section{Examination}

Gait is usually normal but may be antalgic if a recent sprain has occurred. In this case there will be associated swelling around the lateral malleolus but may extend along the joint line of the ankle. Assess for hindfoot varus malalignment. This deformity may be subtle, and the presence of a 'peek-a-boo' sign (Figure 2) and lateral foot callosities should be checked for. The Coleman block test is important to assess for the forefoot-driven cavovarus foot. It is very important that a varus malalignment is adequately corrected when associated with CLAI. ${ }^{22}$

Tenderness is usually present around the anatomical areas of the ligaments but should also be checked for along the ankle joint line, medial malleolus, syndesmosis and base of fifth metatarsal. Range of motion, assessing for any tendinopathy, strength in the muscle groups around the foot and ankle and, most importantly, a neurovascular assessment needs to be performed.

The lateral ligaments are tested for stability using the anterior drawer and varus stress tests (Figure 3). The anterior drawer test (assess ATFL integrity) is performed by stabilising the tibia with one hand and holding the calcaneus with the other while pulling the foot forward. The varus stress test (assess CFL integrity) is performed by inverting the talus relative to the tibia while maintaining the ankle in neutral. The degree of movement and the quality of the endpoint should be assessed and compared to the opposite side. These tests are thought to be reasonably accurate for diagnosing ligament injury. The sensitivity of the anterior drawer test is reported at $58 \%$ to $84 \%$ and specificity at $96 \%$ to $100 \%$. Sensitivity of the varus stress test is $50 \%$ and specificity $88 \%{ }^{23,24}$ They are, however, unable to objectively quantify the severity of the instability. ${ }^{6}$

\section{Investigations}

\section{X-rays}

In the acute sprain, ankle views should be used to exclude fractures according to the Ottawa rules. For CLAI, stress radiography is
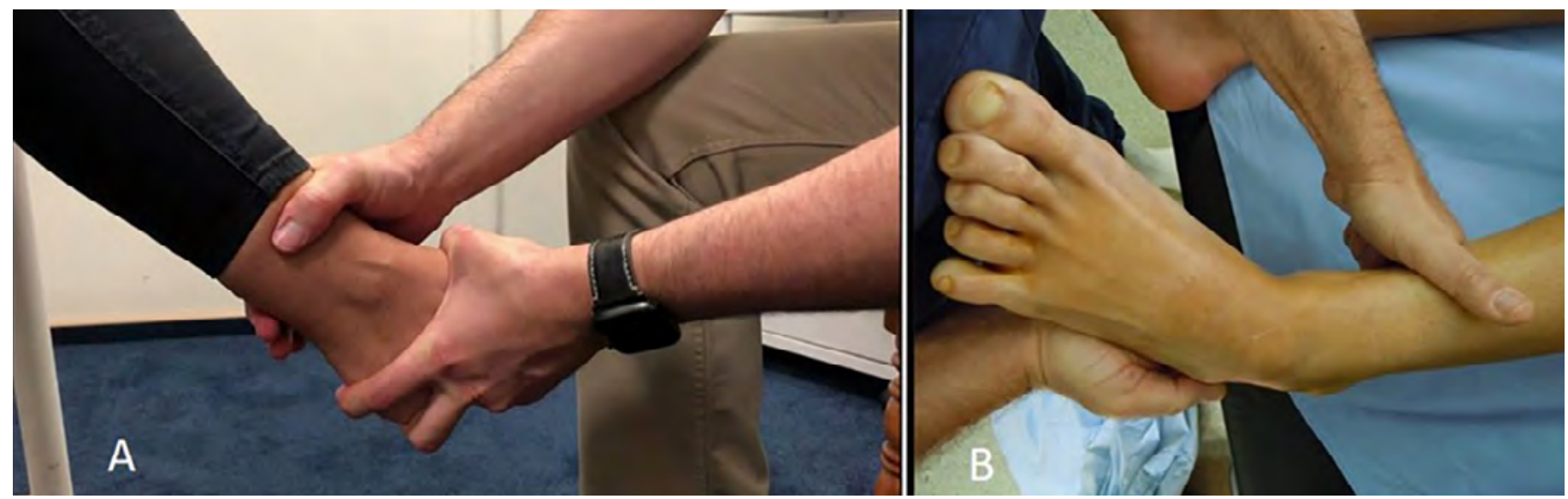

Figure 3. Clinical stress tests. A - anterior drawer test; B - varus stress test 


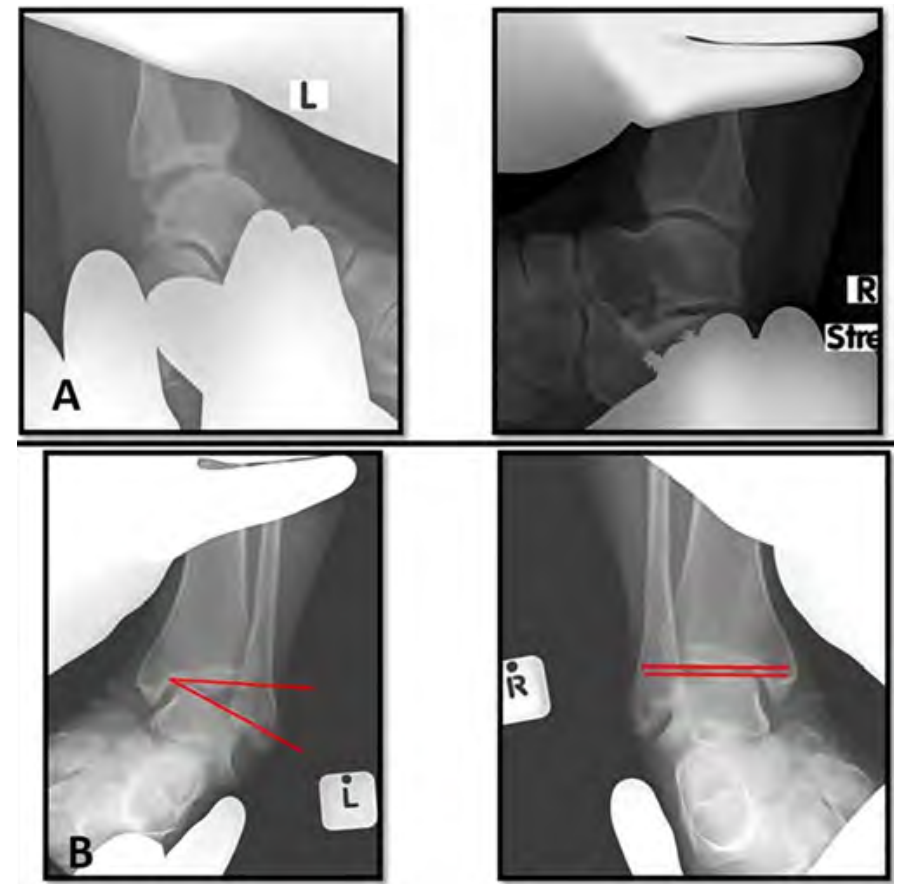

Figure 4. Radiological stress views comparing both ankles. A - anterior talar displacement (drawer) view; B - varus talar tilt view

done which includes anterior talar displacement (drawer) view and varus talar tilt view (Figure 4). Stress may be applied manually or with stress devices like the Telos SE $2000^{\circledR}$ (Telos $\mathrm{GmbH}$, Marburg, Germany). Some authors have questioned the usefulness of the stress X-rays stating that there is not much more that can be gained from them as compared to clinical assessment. ${ }^{6,7}$ Despite this, stress radiography is the 'gold standard' for diagnosing mechanical instability. Karlsson et al. have been quoted as defining an anterior translation of $10 \mathrm{~mm}$ or a talar tilt of $9^{\circ}$ as diagnostic. ${ }^{7}$ Furthermore, a draw of $3 \mathrm{~mm}$ or a tilt of $3^{\circ}$ greater than the opposite side is significant. ${ }^{7}$ Other authors have defined instability as $2 \mathrm{~mm}$ translation on the anterior drawer view, and $10^{\circ}$ degrees of tilting or $5^{\circ}$ greater than the opposite side on the varus tilt view..$^{25}$ Malliaropoulos et al. also added stress radiography to their staging to cater for an unstable injury. ${ }^{2}$ Instability on the talar tilt test has been shown to correlate with changes on the MRI. This suggested that the talar tilt test is a useful screening tool for the status of the ligament and the decision of a reconstruction versus a repair. ${ }^{26}$ The authors recommend stress radiography as a diagnostic tool. However, it needs to be done correctly, and preferably by the attending orthopaedic surgeon.

\section{Ultrasound}

Ultrasound is a cheap, effective way to assess tears as well as the quality of the ligaments, with the benefit of being a dynamic assessment. Ultrasound is operator-dependent and a musculoskeletal-trained ultrasonographer is preferred. In experienced hands, accuracy ranges between 85 and $95 \% .^{6}$ The quality of ligaments can be assessed to help decide between performing a reconstruction or repair. ${ }^{27}$

\section{MRI}

MRI can be used to assess for ruptures and quality of the ligaments. Morphology of the lateral ligaments has been described in various papers as absent, thin, hypertrophied or thickened, and wavy or irregular. Ligaments can also be assessed for continuity by the presence of an intraligamentous signal. ${ }^{26,28}$ Normal thickness is defined between 1 and $3.2 \mathrm{~mm}$. This can assist in preoperative decision-making as to whether ligaments are reparable or if a reconstruction is required. Reconstruction would be needed if ligaments are thin $(<1 \mathrm{~mm}$ thickness) or absent. The intraobserver reliability is around $80 \%(77.3-81.8)$ and interobserver reliability is between $68.2 \%$ and $90.9 \% .^{6,26,28}$ The decision-making based on MRI findings, however, is not well set out or validated yet, and the final decision is dictated by the surgeon's experience and findings at the time of surgery. Besides assessment of the ligaments, associated pathologies like OLTs and anterolateral impingement can also be identified. A drawback of MRI is that it gives a static assessment of the quality of the ligaments with no direct assessment of its mechanical properties. . $^{6,26,28}$

\section{Management}

\section{Nonoperative management}

Nonoperative management is the mainstay for management of LAI in the acute setting. ${ }^{29-31}$ Broström stated that primary surgical repair should not be the routine in acute injuries. ${ }^{29}$ Surgical repair has only been recommended in patients undergoing surgery for an associated injury or fracture, in the acute setting. Surgery may also be considered in elite athletes but this is controversial. ${ }^{30,31}$ Therefore, acute lateral ligament injuries should be managed conservatively. Management and rehabilitation protocols follow a stepwise regimen that follows the phases of ligament healing. Initially, management of the inflammation is focused on reduction of swelling and pain. Most will tend to follow the RICE protocol. This involves rest, ice, compression and elevation. Protection and immobilisation in the form of a cast or moonboot may be used for a short period, noting that prolonged immobilisation is not recommended. Immobilisation is known to cause loss of ligament strength and muscle mass and should not be continued beyond two weeks. Braces, strapping and orthotics have also been used. Inflammation commonly lasts about ten days. ${ }^{7,30}$

The next phase of healing is proliferation. Rehabilitation generally focuses on motion, strengthening, coordination and proprioception. This can last up to eight weeks. This usually involves the use of eversion strengthening and inclines. The evertors have been shown to be an excellent dynamic splint to inversion. ${ }^{7,30}$

Lastly, during remodelling, the emphasis turns to endurance and balance. This can be achieved with trampolines, balance boards and wobble boards. Aerobic fitness is maintained with crosstraining. ${ }^{7,17,30}$ Activity-specific exercises with progression from low level to full activity specific exercises are started from week $10 .^{29}$

In the chronic setting, the emphasis has been on initial nonoperative management, with most studies stating that patients receive full conservative management before surgery is considered. This is especially important for cases of functional CLAl. Karlsson et al. have been quoted as reporting improvement in $50 \%$ of patients with CLAl using a structured rehabilitation programme, with the emphasis on functional rehabilitation. ${ }^{7}$ Peroneal reaction times were found to be longer in patients with CLAl and needed to be addressed, as were proprioception and coordination. Patients with functional instability benefit more than those with mechanical instability from nonoperative treatment. A delay in surgery for CLAI has not been shown to adversely affect outcomes. . $^{7,17,31}$

\section{Operative management}

Operative management of CLAl is indicated for obvious mechanical instability and failed conservative management ${ }^{4}$ (Figure 5). The patient must have both symptoms and objective findings of 


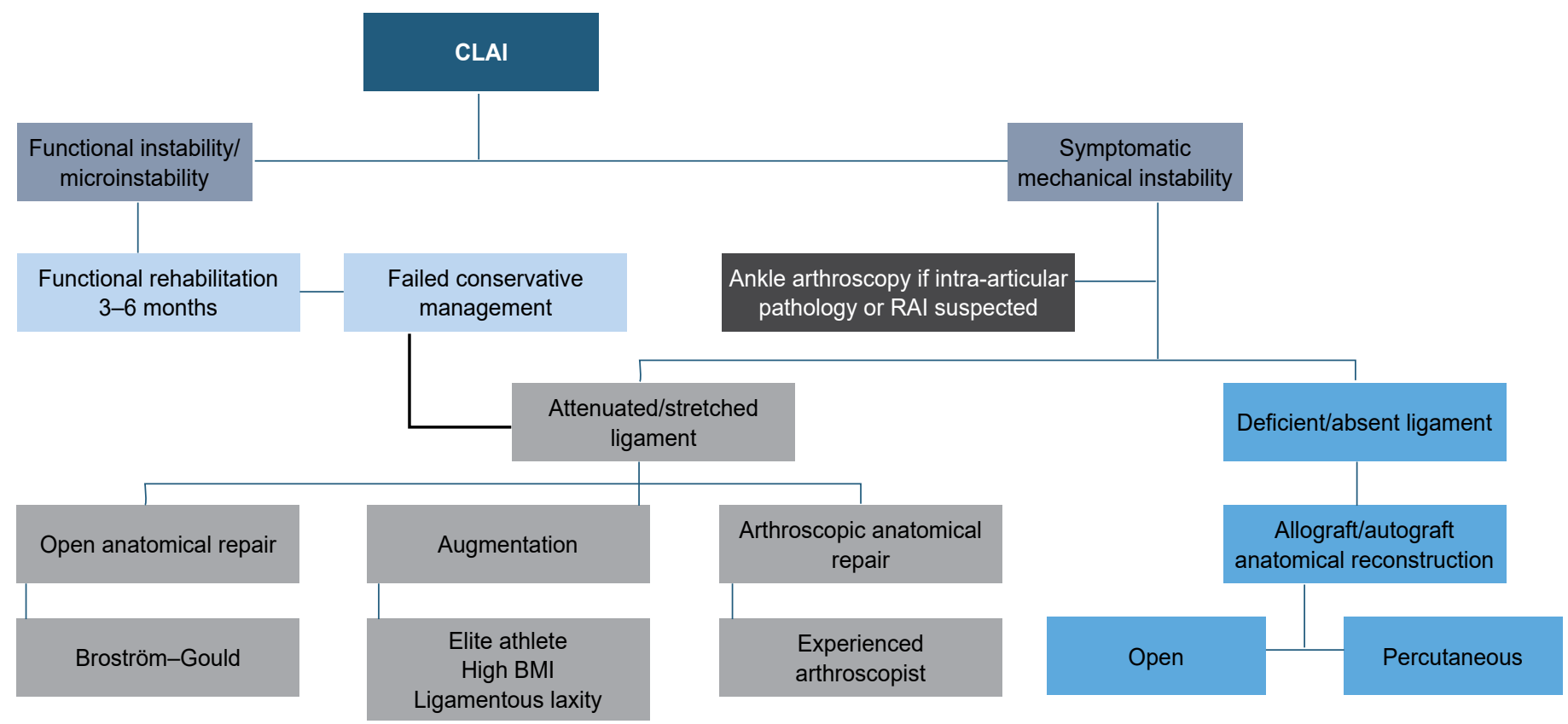

Figure 5. Management algorithm for CLAl

instability. Many procedures have been described. The procedures can be divided up into anatomical and non-anatomical, depending on whether they restore or replicate normal anatomy or not. Further subdivisions can be made regarding repair versus reconstructions, and recently, open versus percutaneous or arthroscopic procedures. .,12,32 $^{2}$

Management of CLAl is incomplete without addressing varus malalignment of the tibia or hindfoot. Failure to address this will lead to excessive stress on the repair and will lead to failure. Associated pathologies need to be treated at the same time. It is imperative that these problems are addressed for a successful outcome. ${ }^{33}$ Contraindications to CLAl surgery include neuroarthropathy, spasticity, peripheral vascular disease and a noncompliant patient.

\section{Open techniques}

\section{Anatomical}

This group of procedures either repair the native ATFL and CFL or use a tendon graft reconstruction to restore the normal anatomical configuration of the ligaments. By restoring the normal anatomy, it allows for normal ankle and subtalar joint kinematics to be maintained. The Broström procedure, which was described in 1966 , is arguably the most reported procedure for the management of CLAl and has been the basis of many of the procedures used today. It is a suture repair of primarily the ATFL but can include the
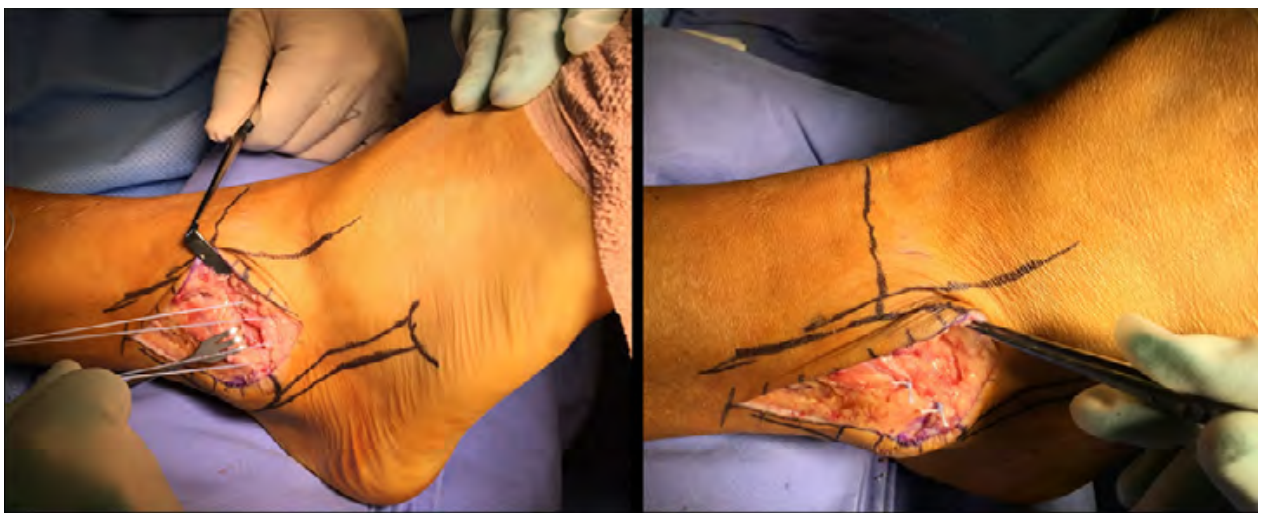

Figure 6. Broström procedure
CFL if it is also involved (Figure 6). Broström himself reported good results with the procedure. Many, however, felt the need to augment the repair and protect it. This resulted in what is today the gold standard in surgical repair of CLAI, known as the Broström-Gould procedure. The Broström repair is augmented with the inferior extensor retinaculum which is pulled up over the repair in a pantsover-vest fashion; this is known as the Gould modification. The Gould modification has been shown to increase the biomechanical strength of the repair by $60 \%$ and more closely restore ankle joint contact pressures. Since the inferior retinaculum attaches to the calcaneus distally, by advancing it onto the fibula, the subtalar joint is also stabilised. ${ }^{17,33,34}$

Over the years, many modifications have been made to the Broström technique and many different augments have also been used. One of the more recently described is the Internal Brace ${ }^{\circledR}$ (Arthrex, Naples, FL). The Internal Brace ${ }^{\circledR}$ is a suture tape that is placed extracapsularly to protect the ligament repairs by acting as a check-rein (Figure 7). Biomechanical studies have shown increased ultimate load to failure as compared to isolated repairs. Cho et al. have reported improved isokinetic peroneal strength

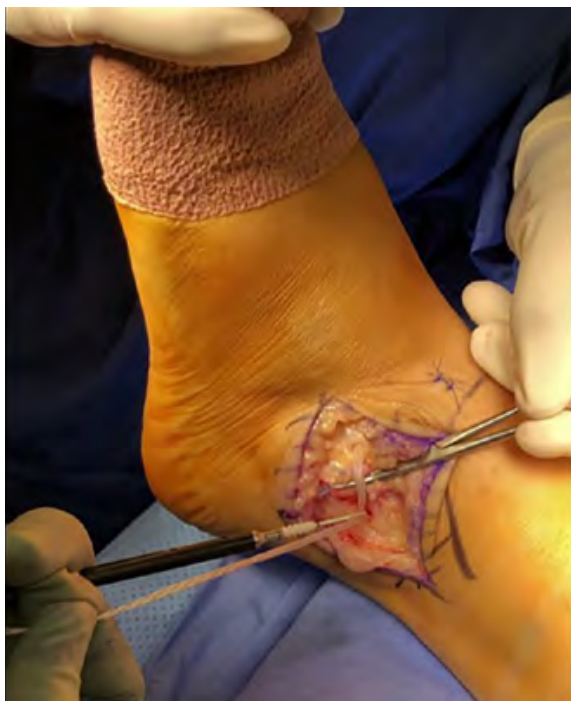

Figure 7. Internal Brace ${ }^{\circledR}$ 
and postural control when a suturetape is added to the repair. These augments have resulted in significant improvements in outcome scores as well as decreased talar tilt and anterior translation. ${ }^{35,36}$ These studies were not comparative studies. These results have to be tempered against the potential for surgical complications and long-term effects of this foreign body. Appropriate indications for using the Internal Brace ${ }^{\circledR}$ include hyperlaxity and revision cases. ${ }^{4,30}$ The Internal Brace ${ }^{\circledR}$ must be used judiciously and not as a matter of routine. There must be decent quality ligament available for repair as these artificial augments are not a replacement for absent soft tissue.

In certain cases, repair of the liga-

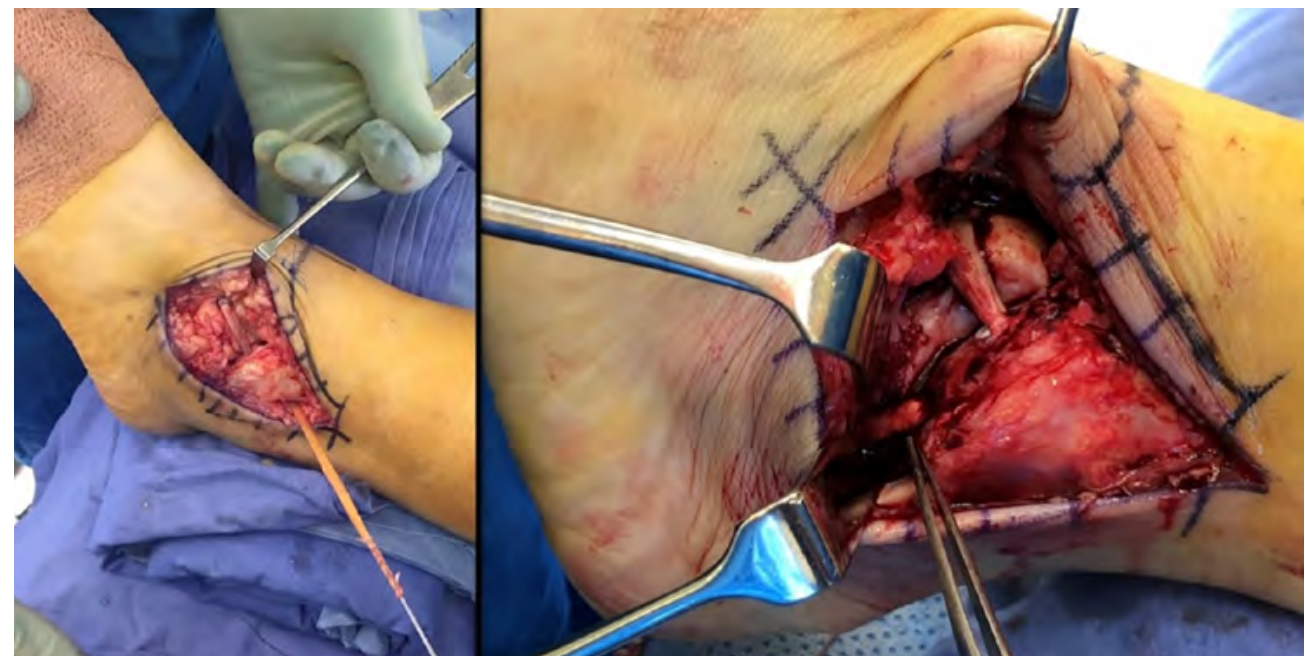

Figure 8. Allograft reconstruction ments is just not possible. The quality of the tissue may be too poor for an adequate repair, or the ligaments may be completely absent. This is likely to be the case in patients with long-standing instability with many recurrent sprains, or those with failed previous surgery. In these cases, a reconstruction is needed. This can be achieved with a tendon autograft or allograft, (Figure 8) placed anatomically at the footprints, to replicate the normal anatomy of the native ligaments. ${ }^{12,30}$ As a group, anatomical repairs and reconstructions have shown high satisfaction and function rates by $\mathrm{Li}$ et al. in a 5-10 year follow-up study. ${ }^{37}$ In a systematic review, Brambilla et al. have shown no evidence of superiority of either autograft and allograft, but noted a lack of good quality studies. ${ }^{38}$

\section{Non-anatomical}

Non-anatomical procedures do not re-create the normal anatomy of the ligaments. Most procedures use the peroneus brevis as a transfer. It is interesting to note that these procedures pre-date the Broström procedure and were the first procedures described for CLAl. The most reported on non-anatomical procedures include the Watson-Jones and Chrisman-Snook. They were thought to be more useful in patients with hyperlaxity or obesity and revision cases. ${ }^{12,31}$ As a group they alter kinematics in the ankle and subtalar joints and have shown to produce stiffness resulting in unsatisfactory long-term results. ${ }^{36}$ As a result, these procedures have fallen out of favour in preference to anatomical procedures. ${ }^{39}$

\section{Minimally invasive}

Minimally invasive surgery (MIS) has become the latest buzz word in foot and ankle surgery. With regard to CLAI, this is no different. This phenomenon has been described as a new wave in the treatment of $\mathrm{CLAl}^{10}$ and part of the natural progression in surgical management of CLAI. Arthroscopic techniques have the advantage of dealing with other associated pathologies like OLTs through the same approach. ${ }^{40}$ There is a lot of hype around these techniques currently, with many articles being published regarding MIS for CLAI. Potential advantages are shorter rehabilitation times and smaller incisions. Development of these techniques has rejuvenated the interest in basic anatomy and biomechanics to help refine and develop these techniques. ${ }^{13,14,41-43}$

Minimally invasive procedures can be separated into arthroscopic and percutaneous. The arthroscopic procedures include repairs and reconstructions, while the percutaneous group includes only reconstructions. The repairs are essentially arthroscopic modifications of the Broström. One of the techniques even bears the name Arthroscopic Broström. ${ }^{44}$ The procedures can be divided

into three categories, namely, arthroscopically assisted, allinside and inside-out techniques. Reconstructions can be done arthroscopically or percutaneously, using either allografts or autografts. The percutaneous techniques are thought to be easier than their arthroscopic counterparts, with the disadvantage of not being able to manage associated intra-articular pathologies without the addition of an arthroscopy prior to doing the reconstruction. Arthroscopy or fluoroscopy is used to find the relevant footprints for graft placement in these minimally invasive techniques. These techniques show a lot of promise. . $^{38,45-47}$

Most papers, however, are low level studies, or papers written by the developers of these techniques. We found no level 1 studies to promote these techniques over open procedures. ${ }^{16,22,33,39,40,43,48-52}$ A systematic review has also borne this out and concluded that there was no clinical evidence to support the advantages of arthroscopic techniques. Added to this, a higher complication rate was reported as compared to open Broström-Gould procedures (11.5\% compared to $5.4 \%$ ). The most commonly reported complication was superficial peroneal nerve injury (4\%), which included neuritis, damage and numbness. ${ }^{53}$ Evidence supporting the use of arthroscopic procedures is limited at present. ${ }^{36}$

Matsui et al. also concluded that there is limited and poorquality evidence which is insufficient to allow a high grade of recommendation to support the use of MIS in treating CLAI. Of 33 studies which met their inclusion criteria, most of them were level 4 and 5 evidence, with only two being level $3 .^{54}$

Arthroscopy is advisable prior to the ligament repair. It must definitely be considered in patients complaining of a dull deep ankle pain, the MRI reporting intra-articular pathology and to assess for RAl if suspected. A note of caution when considering a scope followed by an open procedure; the extravasation of fluid may waterlog the tissue and distort the anatomy.

\section{The elite athlete}

Up to $40 \%$ of all athletics-related injuries involve the lateral ankle ligaments and are commonly seen in sports such as football, basketball, running and dance activities. . $^{21,52,55}$

As with most sports injuries, most studies regarding ankle ligament injuries are reported on the athletic population resulting in most of the advances in management. The demanding nature of professional sport, the fact that the athletes are extremely motivated and have access to excellent rehabilitation teams, results in the boundaries being pushed and necessitating more innovative strategies and research. Unfortunately, this puts immense pressure on the treating physician. The need to return to play as 
soon as possible is enormous and the danger of ending a career is always present. Controversies centre around management of acute sprains, particularly grade III injuries. Indications for surgery in this group include the ability to deal with associated injuries and shortened time for return to play. There is controversy around timing of surgery and the extent to which nonoperative management should be pursued prior to doing surgery. ${ }^{21,56,57}$

In the elite athlete the mainstay of treatment, as in the general population, is functional treatment/exercise training with additional mechanical bracing. Up to $30 \%$ of patients sustaining a grade III injury to the lateral collateral ligament complex can experience ongoing symptoms namely, pain, swelling and instability. In attempting to avoid these complications, early surgical treatment of these high-grade injuries is considered in the athlete. ${ }^{21,58}$ This, however, needs to be balanced against the potential risks of surgery. ${ }^{58,59}$

Most treating physicians agree that in grade I and II injuries in the elite athlete, a trial of nonoperative treatment should be initiated due to ease of implementation, lower cost, and avoidance of surgical complications. In the elite athlete with a grade III injury, early surgery to allow faster return to play can be considered on a case-by-case basis. ${ }^{56,58}$ Identifying which athletes will do better with acute surgical intervention as opposed to a trial of nonoperative management is difficult. The decision eventually boils down to imaging results, the athlete's symptoms and the clinician's experience that the healing response would be inadequate for that athlete. ${ }^{55,56,58}$

Lateral ankle ligament repair has been reported to be safe and effective for grade III injuries in the elite athlete..$^{31,58,60}$ It provides a stable ankle, with level 3 studies showing a return to sport at approximately three months. Where surgery gave longer return times than functional rehabilitation in the past, they are now comparable. These studies are, however, done in high-volume centres with experienced surgeons, highly motivated patients, and accelerated rehabilitation protocols. It should also be kept in mind that even though it is attractive to surgically address acute injuries in the elite athlete, there is no medical urgency as the results of delayed repair or reconstruction are comparable and satisfactory. ${ }^{31,58,60}$

\section{Conclusion}

Injuries to the lateral ankle ligaments are common. Most of these are effectively treated by nonoperative measures in the acute setting. The few that do develop CLAl should first undergo a full assessment to differentiate between functional and mechanical instability. Patients with functional instability are best managed with functional rehabilitation. Patients with objective mechanical instability are managed surgically. The exact procedure should be decided on an individualised basis. An anatomical repair such as the Broström-Gould is still the gold standard; however, newer minimally invasive techniques show promise in surgeons experienced with arthroscopic techniques. If poor or inadequate tissue is available to repair, an anatomical reconstruction using a tendon graft is advised. The elite athlete may benefit from early surgical intervention for acute grade III injuries.

\section{Ethics statement}

The authors declare that this submission is in accordance with the principles laid down by the Responsible Research Publication Position Statements as developed at the 2nd World Conference on Research Integrity in Singapore, 2010. Ethical approval was not obtained (review article).

\section{Declaration}

The authors declare authorship of this article and that they have followed sound scientific research practice. This research is original and does not transgress plagiarism policies.

\section{Author contributions}

$\mathrm{ZM}$ was the main author responsible for drafting of the article, and was assisted by PNFF, NPS and RP. ZM, NPS and PNFF were responsible for article design. PNFF and NPS were responsible for editing, critical review, and final approval of the published version. All authors contributed to conception and literature review on the topic. These include ZM, PNFF, NPS, RP, SKMM, AA, HE, HE, MAK, MM, MJT, AS and MW.

\section{ORCID}

Mayet Z https://orcid.org/0000-0002-7340-3148

Ferrao PNF 19 https://orcid.org/0000-0003-4639-0326

Saragas NP https://orcid.org/0000-0002-5566-7588

Paterson R https://orcid.org/0000-0002-2956-4374

Magobotha SKM (1) https://orcid.org/0000-0003-4774-0420

Alexander A https://orcid.org/0000-0002-4023-7550

Eshragi H https://orcid.org/0000-0002-6714-6691

Ittehadi H https://orcid.org/0000-0002-0556-3553

Khademi MA https://orcid.org/0000-0003-3167-7797

Mehtar M https://orcid.org/0000-0002-8372-0446

Tladi MJ https://orcid.org/0000-0003-4997-3009

Strydom A 19 https://orcid.org/0000-0002-4915-8816

Workman M https://orcid.org/0000-0002-7999-9069

\section{References}

1. Ferran NA, Maffulli N. Epidemiology of sprains of the lateral ankle ligament complex. Foot Ankle Clin. 2006;11(3):659-62. https://doi.org/10.1016/j. fcl.2006.07.002

2. Malliaropoulos N, Papacostas E, Papalada A, Maffulli N. Acute lateral ankle sprains in track and field athletes: an expanded classification. Foot Ankle Clin. 2006;11(3):497-507. https://doi.org/10.1016/j.fcl.2006.05.004.

3. Ajis A, Younger ASE, Maffulli N. Anatomic repair for chronic lateral ankle instability. Foot Ankle Clin. 2006;11(3):539-45. https://doi.org/10.1016/j. fcl.2006.07.005

4. Porter DA, Kamman KA. Chronic lateral ankle instability: open surgical management. Foot Ankle Clin. 2018;23(4):539-54. https://doi.org/10.1016/j. fcl.2018.07.002.

5. Yeung MS, Chan $\mathrm{KM}$, So $\mathrm{CH}$, Yuan WY. An epidemiological survey on ankle sprain. Br J Sports Med. 1994;28(2):112-16. https://doi.org/10.1136/ bjsm.28.2.112.

6. Griffith JF, Brockwel J. Diagnosis and imaging of ankle instability. 2006;11:47596. https://doi.org/10.1016/j.fcl.2006.07.001.

7. Ajis A, Maffulli N. Conservative management of chronic ankle instability. 2006;11:531-37. https://doi.org/10.1016/j.fcl.2006.07.004.

8. Konradsen L, Bech L, Ehrenbjerg M, Nickelsen T. Seven years follow up after ankle inversion trauma. Scand J Med Sci Sport. 2002;12:129-35.

9. Wells B, Allen C, Deyle G, Croy T. Management of acute grade II lateral ankle sprains with an emphasis on ligament protection: a descriptive case series. Int J Sports Phys Ther. 2019;14(3):445-58. https://doi.org/10.26603/ ijspt20190445.

10. Vega J, Karlsson J, Kerkhoffs GMMJ, Dalmau-Pastor M. Ankle arthroscopy: the wave that's coming. Knee Surgery, Sport Traumatol Arthrosc. 2020;28(1):57. https://doi.org/10.1007/s00167-019-05813-8

11. Bozkurt M, Nedim M. Anatomic factors and biomechanics in ankle instability Foot Ankle Clin. 2006;11:451-63. https://doi.org/10.1016/j.fcl.2006.06.001.

12. Espinosa N, Smerek J, Kadakia AR, Myerson MS. Operative management of ankle instability: reconstruction with open and percutaneous methods. Foot Ankle Clin. 2006;11:547-65. https://doi.org/10.1016/j.fcl.2006.07.003.

13. Matsui K, Takao M, Tochigi $Y$, Ozeki S. Anatomy of anterior talofibular ligament and calcaneofibular ligament for minimally invasive surgery : a systematic review. Knee Surgery, Sport Traumatol Arthrosc. 2017;25(6):1892-902. https:// doi.org/10.1007/s00167-016-4194-y.

14. Vega J, Malagelada F, Manzanares Céspedes MC, Dalmau-Pastor M. The lateral fibulotalocalcaneal ligament complex: an ankle stabilizing isometric structure. Knee Surgery, Sport Traumatol Arthrosc. 2020;28(1):8-17. https://doi. org/10.1007/s00167-018-5188-8

15. Miller Mark TS, editor. SECTION C adult. In: DeLee and Drez's Orthopaedic Sports Medicine. 3rd ed. Saunders; 2009.

16. Acevedo JI, Palmer RC, Mangone PG. Arthroscopic treatment of ankle instability: Brostrom. (Ankle instability arthroscopy Brostrom, Ankle sprain lateral ligament repair.) Foot Ankle Clin. 2020;23(4):555-70. https://doi. org/10.1016/j.fcl.2018.07.003.

17. Sarcon AK, Heyrani N, Giza E, Kreulen C. Lateral ankle sprain and chronic ankle instability. Foot Ankle Orthop. 2019;4(2):247301141984693. https://doi. org/10.1177/2473011419846938. 
18. Buchhorn T, Sabeti-Aschraf M, Dlaska CE, et al. Combined medial and lateral anatomic ligament reconstruction for chronic rotational instability of the ankle. Foot Ankle Int. 2011;32(12):1122-26. https://doi.org/10.3113/FAI.2011.1122.

19. Vega J, Allmendinger J, Malagelada F, Guelfi M, Dalmau-Pastor M. Combined arthroscopic all-inside repair of lateral and medial ankle ligaments is an effective treatment for rotational ankle instability. Knee Surgery, Sport Traumatol Arthrosc. 2020;28(1):132-40. https://doi.org/10.1007/ s00167-017-4736-y.

20. DiGiovanni BF, Fraga CJ, Cohen BE, Shereff MJ. Associated injuries found in chronic lateral ankle instability. Foot Ankle Int. 2000;21(10):809-15. https://doi. org/10.1177/107110070002101003.

21. Camacho LD, Roward ZT, Deng Y, Daniel Latt $L$. Surgical management of lateral ankle instability in athletes. J Athl Train. 2019;54(6):639-49. https://doi. org/10.4085/1062-6050-348-18.

22. Acevedo JI, Mangone P. Arthroscopic brostrom technique. Foot Ankle Int. 2015;36(4):465-73. https://doi.org/:10.1177/1071100715576107.

23. Van Dijk CN, Lim LSL, Bossuyt PMM, Marti RK. Physical examination is sufficient for the diagnosis of sprained ankles. J Bone Jt Surg - Ser B. 1996;78(6):958-62. https://doi.org/10.1302/0301-620X78B6.1283.

24. Hertel J, Denegar CR, Monroe MM, Stokes WL. Talocrural and subtalar joint instability after lateral ankle sprain. Med Sci Sports Exerc. 1999;31(11):1501508. https://doi.org/10.1097/00005768-199911000-00002.

25. Shakked RJ, Karnovsky S, Drakos MC. Operative treatment of lateral ligament instability. Curr Rev Musculoskelet Med. 2017;10(1):113-21. https://doi. org/10.1007/s12178-017-9391-X.

26. Jung HG, Kim NR, Kim TH, Eom JS, Lee DO. Magnetic resonance imaging and stress radiography in chronic lateral ankle instability. Foot Ankle Int. 2017;38(6):621-26. https://doi.org/10.1177/1071100717693207.

27. Salat $P$, Le V, Veljkovic A, Cresswell ME. Imaging in foot and ankle instability. Foot Ankle Clin. 2018;23(4):499-522.e28. https://doi.org/10.1016/j fcl.2018.07.011.

28. Morvan A, Klouche S, Thes A, Hardy P, Bauer T. Reliability and validity of preoperative MRI for surgical decision making in chronic lateral ankle instability. Eur J Orthop Surg Traumatol. 2018;28(4):713-19. https://doi. org/10.1007/s00590-017-2116-4

29. Broström L. Sprained ankles. VI. Surgical treatment of "chronic" ligamen ruptures. Acta Chir Scand. 1966 Nov;132(5):551-65. PMID: 5339635.

30. Strydom A, Saragas N, Ferrao P. Controversies in the treatment of acute ankle ligament sprains in sportsmen and women. Sport Med Updat. 2016;8(4):9-10

31. Slater K. Acute lateral ankle instability. Foot Ankle Clin. 2018;23(4):523-37. https://doi.org/10.1016/j.fcl.2018.07.001.

32. Cao Y, Hong Y, Xu Y, Zhu Y, Xu X. Surgical management of chronic lateral ankle instability: A meta-analysis. J Orthop Surg Res. 2018;13(1):1-15. https:// doi.org/10.1186/s13018-018-0870-6.

33. Pellegrini MJ, Sevillano J, Ortiz C, Giza E, Carcuro G. Knotless modified arthroscopic-Broström technique for ankle instability. Foot Ankle Int. 2019;40(4):475-83. https://doi.org/10.1177/1071100718820341.

34. Zeng G, Hu X, Liu W, et al. Open Broström-Gould repair vs arthroscopic anatomical repair of the anterior talofibular ligament for chronic lateral ankle instability. Foot Ankle Int. 2020;41(1):44-49. https://doi. org/10.1177/1071100719875964.

35. Cho BK, Hong SH, Jeon JH. Effect of lateral ligament augmentation using suture-tape on functional ankle instability. Foot Ankle Int. 2019;40(4):447456 https://doi.org/10.1177/1071100718818554

36. Yasui Y, Shimozono Y, Kennedy JG. Surgical procedures for chronic lateral ankle instability. J Am Acad Orthop Surg. 2018;26(7):223-30. https://doi. org/10.5435/JAAOS-D-16-00623.

37. $\mathrm{Li} \mathrm{H}$, Hua Y, Li H, Chen $\mathrm{S}$. Anatomical reconstruction produced similarly favorable outcomes as repair procedures for the treatment of chronic lateral ankle instability at long-term follow-up. Knee Surgery, Sport Traumatol Arthrosc. 2020:28:3324-29. https://doi.org/10.1007/s00167-018-5176-z.

38. Brambilla L, Bianchi A, Malerba F, Loppini M, Martinelli N. Lateral ankle ligament anatomic reconstruction for chronic ankle instability: Allograft or autograft? A systematic review. Foot Ankle Surg. 2020;26(1):85-93. https://doi. org/10.1016/j.fas.2018.11.014

39. Cordier G, Ovigue J, Dalmau-Pastor M, Michels F. Endoscopic anatomic ligament reconstruction is a reliable option to treat chronic lateral ankle instability. Knee Surgery, Sport Traumatol Arthrosc. 2020;28(1):86-92. https:// doi.org/10.1007/s00167-019-05793-9.

40. Teixeira J, Guillo S. Arthroscopic treatment of ankle instability - allograft/ autograft reconstruction. Foot Ankle Clin. 2018;23(4):571-79. https://doi. org/10.1016/j.fcl.2018.07.004.

41. Acevedo JI, Ortiz C, Golano P, Nery C. ArthroBroström lateral ankle stabilization technique. Am J Sports Med. 2015;43(10):2564-71. https://doi. org/10.1177/0363546515597464.
42. Crombé A, Borghol S, Guillo S, Pesquer L, Dallaudiere B. Arthroscopic reconstruction of the lateral ankle ligaments: Radiological evaluation and short-term clinical outcome. Diagn Interv Imaging. 2019;100(2):117-25. https:// doi.org/10.1016/j.diii.2018.09.002.

43. Cordier G, Lebecque J, Vega J, Dalmau-Pastor M. Arthroscopic ankle lateral ligament repair with biological augmentation gives excellent results in case of chronic ankle instability. Knee Surgery, Sport Traumatol Arthrosc 2020;28(1):108-15. https://doi.org/10.1007/s00167-019-05650-9.

44. Acevedo JI, Mangone P. Arthroscopic Brostrom technique. Foot Ankle Int. 201536(4):465-73. https://doi.org/10.1177/1071100715576107

45. Glazebrook M, Stone J, Matsui K, et al. Percutaneous ankle reconstruction of lateral ligaments (Perc-Anti RoLL). Foot Ankle Int. 2016;37(6):659-64. https:// doi.org/10.1177/1071100716633648.

46. Takao M, Matsui K, Stone JW, et al. Arthroscopic anterior talofibular ligament repair for lateral instability of the ankle. Knee Surgery, Sport Traumatol Arthrosc. 2016;24(4):1003-1006. https://doi.org/10.1007/s00167-015-3638-0

47. Glazebrook M, Eid M, Alhadhoud M, et al. Percutaneous ankle reconstruction of lateral ligaments. Foot Ankle Clin. 2018;23(4):581-92. https://doi. org/10.1016/j.fcl.2018.07.013.

48. Vega J, Guelfi M, Malagelada F, Peña F, Dalmau-Pastor M. Arthroscopic all-inside anterior talofibular ligament repair through a three-portal and no-ankle-distraction technique. JBJS Essent Surg Tech. 2018;8(3):e25.

49. Vega J, Malagelada F, Dalmau M. Arthroscopic all-inside ATFL and CFL repair is feasible and provides excellent results in patients with chronic ankle instability. Knee Surgery, Sport Traumatol Arthrosc. 2020;28(1):116-23. https:// doi.org/10.1007/s00167-019-05676-z.

50. Takao M, Glazebrook M, Stone J, et al. Ankle arthroscopic reconstruction of lateral ligaments (Ankle Anti-ROLL). Arthrosc Tech. 2015;4(5):e595-e600. https://doi.org/10.1016/j.eats.2015.06.008.

51. Glazebrook M, Eid M, Alhadhoud M, et al. Percutaneous ankle reconstruction of lateral ligaments. Foot Ankle Clin. 2018;23(4):581-92. https://doi. org/10.1016/j.fcl.2018.07.013

52. Batista JP, Javier del Vecchio J, Patthauer L, Ocampo M. Arthroscopic lateral ligament repair through two portals in chronic ankle instability. Open Orthop J. 2017;11(1):617-32. https://doi.org/10.2174/1874325001711010617.

53. Brown AJ, Shimozono Y, Hurley ET, Kennedy JG. Arthroscopic repair of lateral ankle ligament for chronic lateral ankle instability: a systematic review. Arthrosc - J Arthrosc Relat Surg. 2018;34(8):2497-503. https://doi.org/10.1016/j. arthro.2018.02.034.

54. Matsui K, Burgesson B, Takao M, et al. Minimally invasive surgical treatment for chronic ankle instability: a systematic review. Knee Surgery, Sport Traumatol Arthrosc. 2016;24(4):1040-48. https://doi.org/10.1007/ s00167-016-4041-1.

55. Thompson JY, Byrne C, Williams MA, et al. Prognostic factors for recovery following acute lateral ankle ligament sprain: A systematic review. BMC Musculoskelet Disord. 2017;18(1):1-14. https://doi.org/10.1186/ s12891-017-1777-9.

56. Slater K. Acute lateral ankle instability. Foot Ankle Clin. 2018;23(4):523-37. https://doi.org/10.1016/j.fcl.2018.07.001.

57. Wei S, Liu S, Han F, Xu F, Cai X. Clinical outcomes of a modified all-inside arthroscopic repair of anterior talofibular ligament for chronic ankle instability: A preliminary report. Med (United States). 2019;98(36):1-7. https://doi. org/10.1097/MD.0000000000016734.

58. Kerkhoffs GMMJ, Van Dijk CN. Acute lateral ankle ligament ruptures in the athlete: the role of surgery. Foot Ankle Clin. 2013;18(2):215-18. https://doi. org/10.1016/j.fcl.2013.02.003.

59. Hunt KJ, Mangone P, Cooper MT, Brigido SA. Update on lateral ankle instability. Foot Ankle Spec. 2018;11(1):67-71. https://doi. org/10.1177/1938640017753170.

60. White WJ, McCollum GA, Calder JDF. Return to sport following acute lateral ligament repair of the ankle in professional athletes. Knee Surgery, Sport Traumatol Arthrosc. 2016;24(4):1124-29. https://doi.org/10.1007/ s00167-015-3815-1. 